\title{
Identification of Acoustic Emission Signals Originating from the Core Magnetization of Power Oil Transformer
}

\author{
Aneta OLSZEWSKA, Franciszek WITOS
}

\begin{abstract}
Department of Optoelectronics, Faculty of Electrical Engineering, Silesian University of Technology Krzywoustego 2, 44-100 Gliwice, Poland; e-mail: \{Aneta.Olszewska, Franciszek.Witos\}@polsl.pl
\end{abstract}

(received August 12, 2016; accepted November 11, 2016)

In this paper, the properties of AE signals originating from phenomena occurring during magnetization of ferromagnetic materials which are used to construct power transformer cores are presented. The AE signals in a selected power oil transformer were recorded and analyzed. The analysis included, i.e., time, frequency, and time-frequency analyses, calculations of amplitude distributions of the signals and defined AE descriptors, determination of the descriptor map on the side walls of transformers, as well as a detailed analysis of selected part of the signals.

The maps of descriptors were analyzed in the frequency bands of $20-70 \mathrm{kHz}, 70-100 \mathrm{kHz}$, and $100-$ $200 \mathrm{kHz}$. The analysis of the properties of the signals was performed in time and frequency domains. Based on the analysis, there were identified the AE signals originating from the phenomena occurring during the core magnetization of a power oil transformer. To identify those phenomena, the maps of the ADC descriptor calculated in the band of $20-70 \mathrm{kHz}$ when selecting the measurement points in which there were no $\mathrm{AE}$ sources from partial discharges were used.

An analysis of magnetoacoustic emission signals in the bands of $70-100 \mathrm{kHz}$ and $100-200 \mathrm{kHz}$ was also performed. The analysis of the signal properties in such an extended frequency range allowed determining the properties of the magnetoacoustic signals coming from core sheets of power oil transformers.

Keywords: power oil transformers; magnetization of transformers cores; magnetoacoustic emission.

\section{Magnetic phenomena in ferromagnetic materials}

Phenomena in ferromagnetic materials are one of the sources of acoustic signals in power oil transformers. During the magnetization of ferromagnetic materials which are used to construct transformer core laminations, there occurs the reversible movement of domain boundaries (the so-called Bloch walls), irreversible movement of domain boundaries (Barkhausen effect), and rotation of magnetization vectors in the direction of the external magnetic field. Within these processes, there occur processes of creation of domain boundaries, movement of these boundaries, and their annihilation.

The Barkhausen jump results in (i) the generation of an electromagnetic wave (Barkhausen field effect HEB), (ii) a local change of the magnetization and defects in the crystal lattice and (iii) the generation of an acoustic wave (magnetoacoustic emission effect).

The phenomenon of magnetoacoustic emission (MAE) consists in generating a sound wave by a jump motion of a $90^{\circ}$ domain wall in a material with non- zero magnetostriction (AUgustyniAK, 1999). A MAE signal depends not only on the microstructure, stresses or the magnetization frequency, but also on the geometry of the sample and its demagnetization.

MAE has a relatively short history. It was first reported by A.E. Lord in the middle 1970-s (LORD,1975). He called that effect "the acoustic Barkhausen effect" by analogy with „the classic Barkhausen effect". Elastic waves generated during MAE are caused by changes in magnetostrictive stresses during the magnetization process. The rate of changes of magnetostrictive stresses is one of more important factors affecting magnetoacoustic emission. It depends on: (i) magnetostrictive properties of the material, (ii) the value of magnetic flux density $B$ inside the material and (iii) the rate of magnetic flux density change $\mathrm{d} B / \mathrm{d} t$ (EDWARds, PALMER, 1987).

M. Guyot and V. Cagan (1993) indicate the presence of two MAE emission maxima. The first one occurs immediately after changing the direction of magnetization and is associated with the creation of domain boundaries. The second one is connected with the movement and annihilation of all domain bound- 
aries. The MAE minimum is in the vicinity of coercive point $H_{C}$.

DEHENG et al. (1988) show that the main frequency band for the magnetoacoustic emission phenomenon in investigations of transformers is $20-65 \mathrm{kHz}$, whereas the total band for the phenomena associated with the magnetization of transformer core sheets (HEB + MAE) is $10-65 \mathrm{kHz}$. Howells et al. (Howells, NoRTON, 1978) determine the frequency range of magnetic noise as 30-60 kHz. In (BENGTSSON et al., 1997), extend the band of signals associated with noises in the core up to $80 \mathrm{kHz}$. From (PIotrowski et al., 2012) it follows that the MAE signal spectrum for steel can reach up to $300 \mathrm{kHz}$.

\section{Research method}

To record AE signals in the investigated power oil transformer, the author's measuring system EA DEMA-COMP (WiTOs, 2008) has been used. It can be used both for research conducted in a laboratory and measurements taken during normal operation of power transformers. Figure 1 shows a general view of the measuring system.

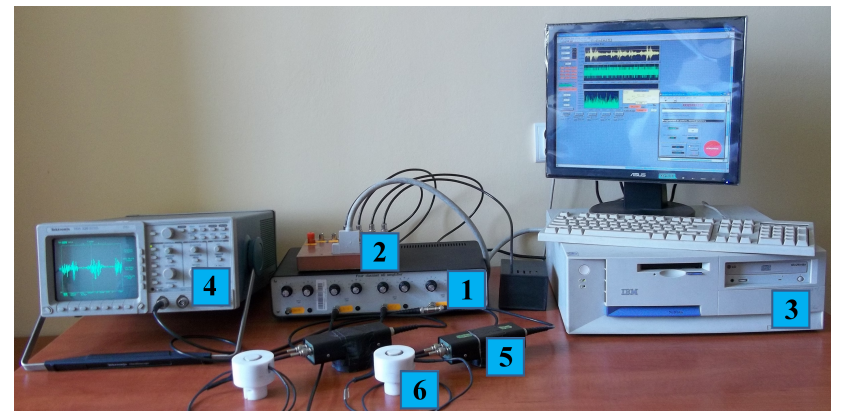

Fig. 1. General view of the measuring system EA DEMACOMP: 1 - apparatus set of DEMA, 2 - PCI-610E measuring card and CB6-TP measuring terminal, 3 - PC computer, 4 - oscilloscope, 5 - preamplifier, 6 - AE measuring sensor. a)
$U_{\min }=-1.62 \mathrm{~V} ;$
$U_{\max }=2.19 \mathrm{~V} ;$
$U_{\mathrm{rms}}=0.123 \mathrm{~V}$

b)

$$
\begin{aligned}
& f_{\max }=55.7 \mathrm{kHz} \\
& U_{\mathrm{rms}}^{2}\left(f_{\max }\right)=1.18 \mathrm{E}-6 \mathrm{~V}^{2}
\end{aligned}
$$
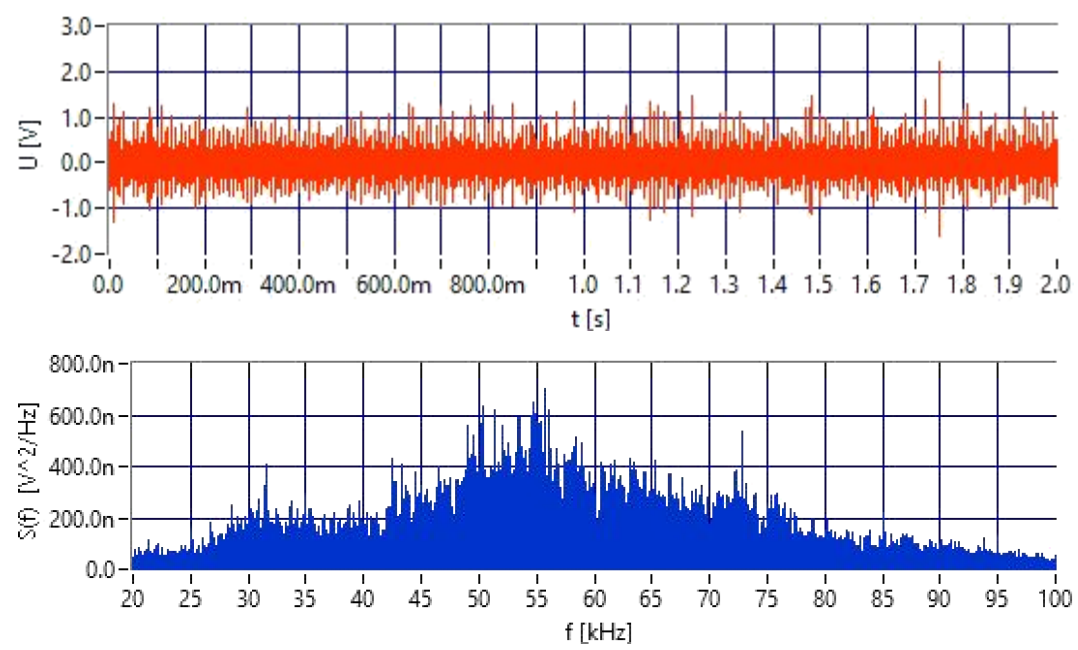

c)

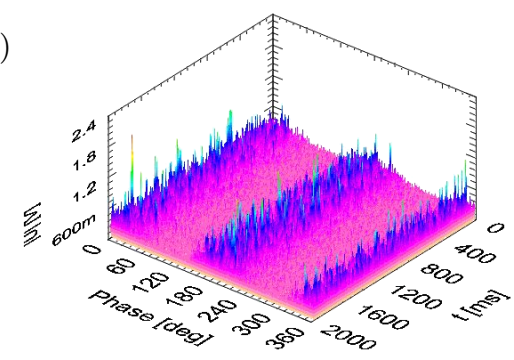

d)

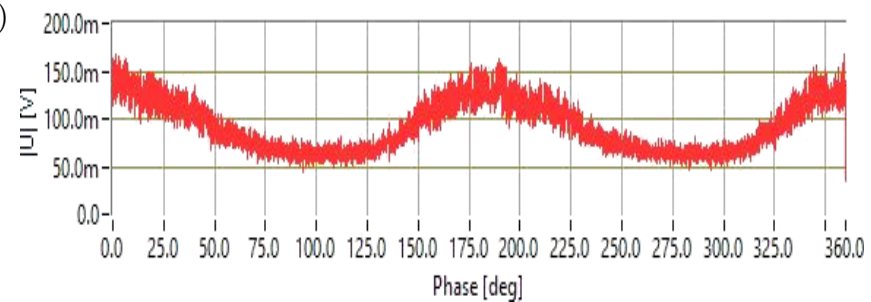

e)

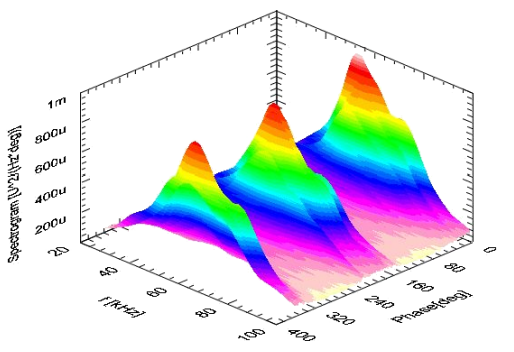

f)

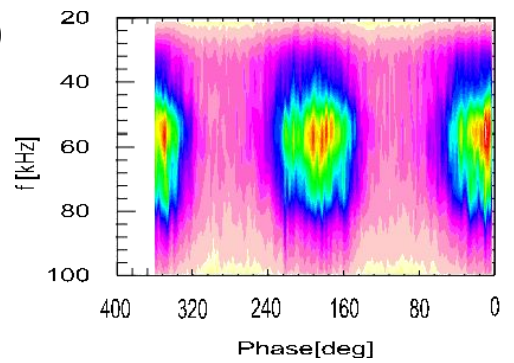

Fig. 2. Basic description of an exemplary AE signal coming from PDs: a) signal after filtration, b) frequency characteristic, c) phase-time characteristic, d) averaged phase characteristic, e) and f) STFT spectrograms. 
AE signals recorded by the measuring system are analyzed by the author's system for AE signal analysis (WiTOs, 2008). The analysis includes the calculation of basic characteristics and amplitude distributions of signals, defined AE descriptors with ADP, ADC, ADNC acronyms (Witos et al., 2002; OlszeWskA, Witos, 2012; Witos, Olszewska, 2012; Witos, Gacek, 2013), determination of maps of descriptors on side walls of transformers, and next location of sources of AE signals as well as the analysis of properties of the signals recorded at the points located in the neighbourhood of the identified sources. Figure 2 presents example characteristics belonging to the basic description of the AE signal recorded in the power oil transformer.

Time waveforms of AE signal (Fig. 2a) are subjected to multiple analysis in discrimination threshold $(U)$. The result of these analyzes are amplitude distributions of: AE count rate, signal power, and $\mathrm{AE}$ normalised activity of counts.

Properties of amplitude distributions of AE (made in logarithmic scale) can be described by means of specially defined AE descriptors. The descriptors were defined as follows. At first, one should mark a fragment of an amplitude distribution curve which corresponds to the range of the discrimination threshold $\left(U_{d}, U_{g}\right)$; value of $U_{d}$ is determined by the minimum of amplitude distribution derivative against the discrimination threshold, whereas $U_{g}$ is $90 \%$ of the maximal value of the recorded signal. The determined fragment of the curve is approximated by a straight line: $\ln \left(\frac{\mathrm{d} N(U)}{\mathrm{d} t}\right)=A U+B$ whereas the descriptor connected with the amplitude distribution is equal to slope of the straight A. ADC descriptor is connected with Amplitude Distribution of AE Counts, ADP descriptor is connected with Amplitude Distribution of AE signal Power and ADNC descriptor is connected with Amplitude Distribution of AE Normalized activity Counts.

The so defined descriptors do not base on the absolute values of the recorded signal. A larger descriptor value (flatter part of the curve) means a more advanced deformational process.

Figure 3 shows the example amplitude distributions of the count rate calculated in the framework of the advanced analysis (Figs. 3a, c), derivatives of these distributions with respect to the threshold of discrimination (Fig. 3b), and corresponding values of the ADC descriptor (Fig. 3d) for two families of AE signals those coming from sources of partial discharges (PDs) (Fig. 3c, signals 1-5) and the noises associated with the measuring channel (Fig. 3c, signals 6-10). One can see a fundamental difference between the descriptor values in those two families, which confirms the assumption of the possibility of recording and identifying AE signals coming from different sources.

The maps of descriptors on the side walls of the investigated transformer tank are determined from the obtained descriptors with the use of the kriging method. On the maps, there are local maxima. Figure 4 shows an exemplary map of an ADC descriptor a)

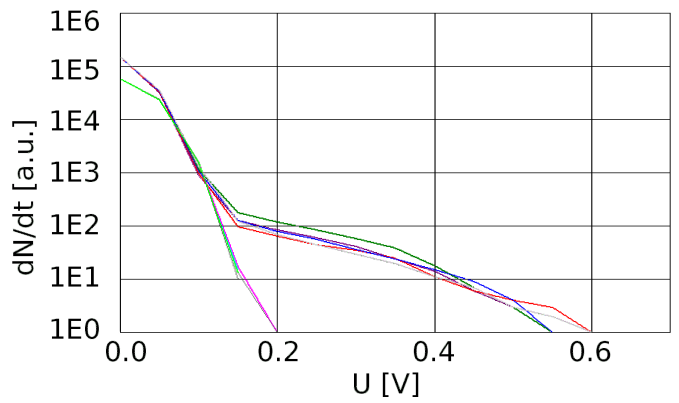

c)

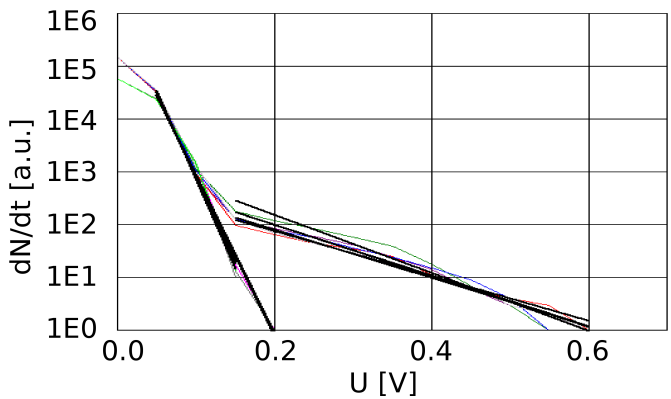

b)

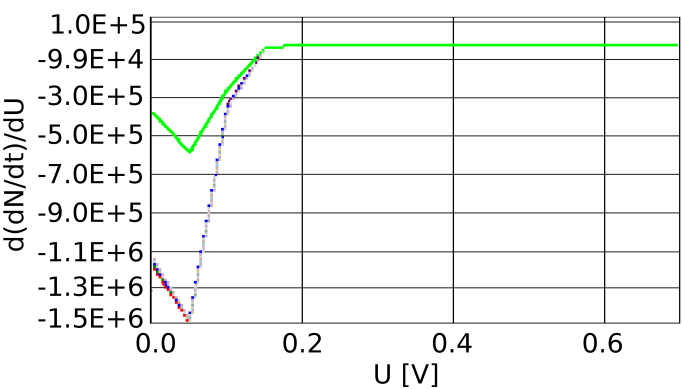

d)

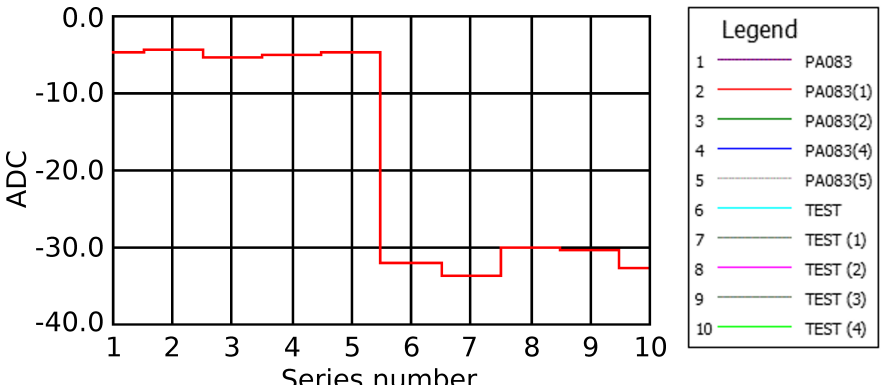

Fig. 3. Investigation of amplitude distributions by means of AE descriptor methods (calculation and visualization of amplitude distributions and descriptors): results for the family of AE signals coming from PD (signals 1-5) and the family of noise within measuring line (signals 6-10). 


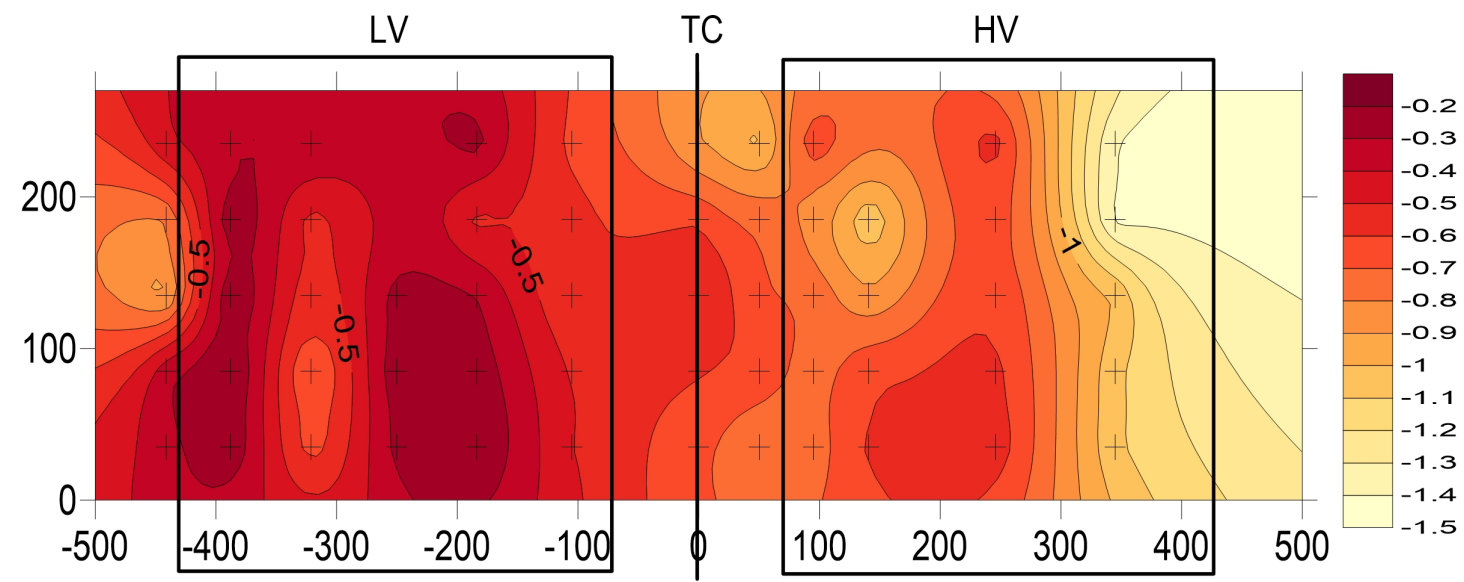

Fig. 4. Map of ADC descriptor on the side walls of the tested transformer tank for the analysis of signals in the range $20-200 \mathrm{kHz} .(X, Y)$ coordinates of the transformer tank points (in centimeters): $X$ - running position along the transformer tank, 0 - center of the tap changer (TC), positive values of $X$ - part of the tank from high voltage side (HV), negative values of $X$ - part of the tank from low voltage side $(\mathrm{LV}), Y$ - running height of the transformer tank, + - marked measurement points.

calculated for the frequency band of $20-200 \mathrm{kHz}$. On these maps, one can determine the areas with the local maxima. This enables the analysis of AE signals recorded in selected areas aiming at identification of signals coming from different acoustic sources in power oil transformers and location of these sources in the investigated transformers.

Next the selected parts of the AE signals of the duration equal or shorter than one period of the refer- ence voltage are additionally analyzed. An exemplary analysis of the part of the recorded AE signal is shown in Fig. 5. In the analysis, there is selected part of the whole recorded signal of the duration equal to one period of the reference voltage. This part is filtrated in a selected frequency band, and then there are separated single structures from the signal (Fig. 5a) for which the duration and frequency characteristic are determined (Fig. 5b).

a)

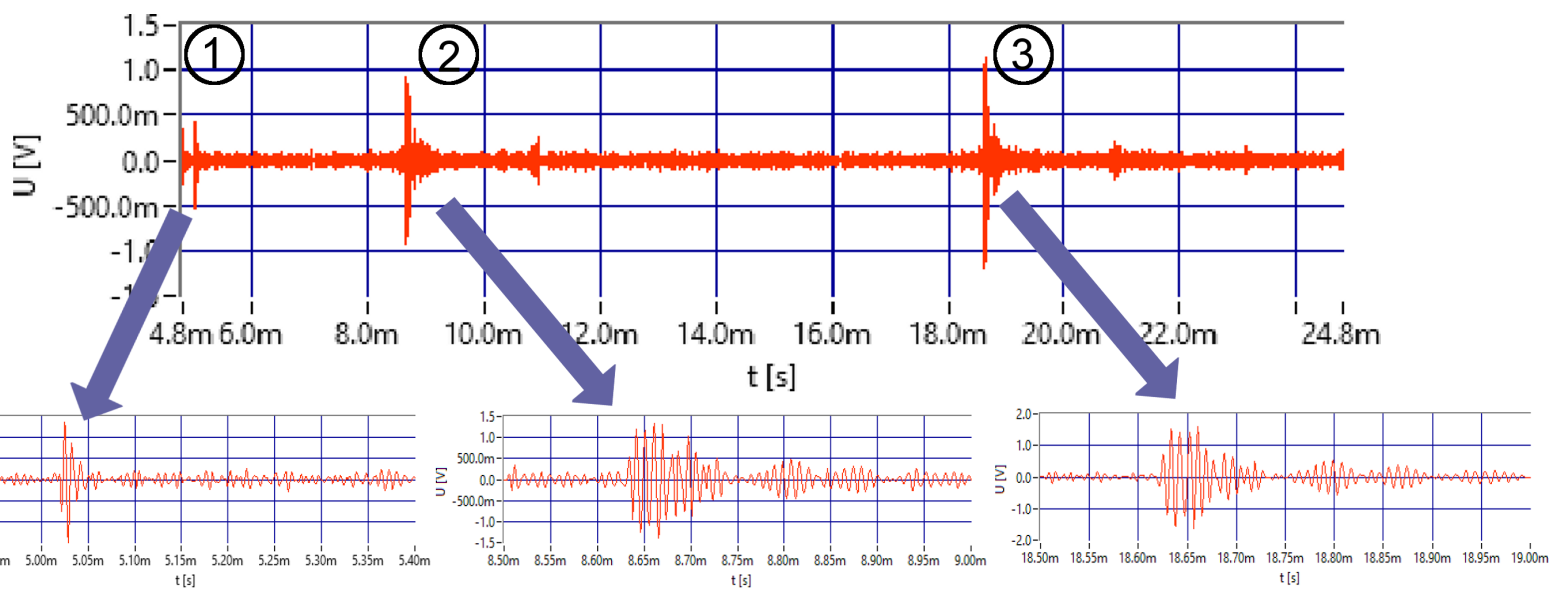

b)

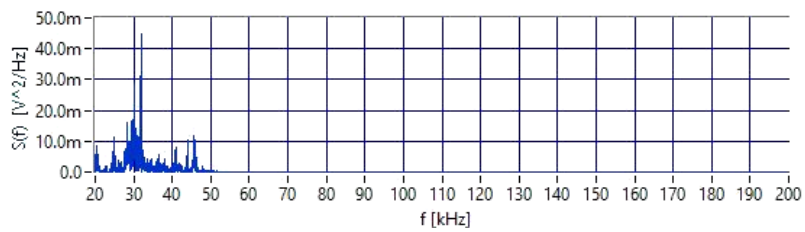

c)

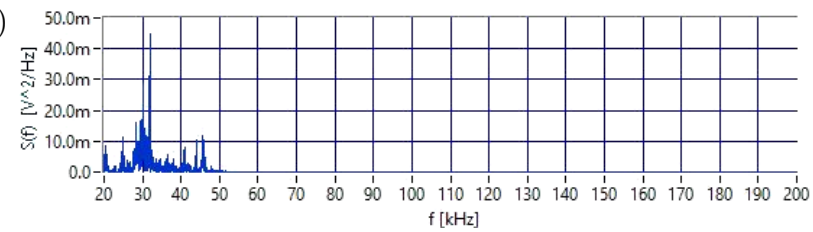

Fig. 5. Analysis of a selected part of the signal of duration equal to one period of the reference voltage, recorded at a chosen measurement point: a) selected part of the signal after filtration together with the shown single pulses, b) frequency characteristics for the selected part of the signal in the frequency range $20-200 \mathrm{kHz}, \mathrm{c}$ ) frequency characteristics for the selected part of the signal in the frequency range $110-200 \mathrm{kHz}$. 


\section{Identification and properties of AE signals coming from phenomena occurring during magnetization of a power oil transformer core}

Identification of $\mathrm{AE}$ signals coming from the phenomena occurring during the magnetization of ferromagnetic materials will be presented based on the analysis of the $\mathrm{AE}$ signals recorded in the investigated power transformer with a ratio of $110 / 20 / 6 \mathrm{kV}$ and rated power of 25 MVA. The transformer has been operating faultlessly for the whole operating life.

Due to the fact that the lower limit of frequency range of the measuring system used in the research equals $20 \mathrm{kHz}$, the analysis will be carried out in the range of $20-70 \mathrm{kHz}$.

On the map of the ADC descriptor in the band of $20-70 \mathrm{kHz}$ (Fig. 6a), the areas of the greatest intensity of the AE signals were determined provided that the corresponding with them descriptor values in the range of $110-200 \mathrm{kHz}$ were small. These areas determine the places in which MAE signals are dominant in the recorded signals. To identify the AE signals coming from these phenomena, there were performed analyses of the $\mathrm{AE}$ signals recorded in the following areas:

a) vicinity of the measurement point PA032 with coordinates $X=385 \mathrm{~cm}, Y=95 \mathrm{~cm}$,

b) measurement points belonging to the family PA02y with coordinates $X=483 \mathrm{~cm}, Y=$ $60 \div 235 \mathrm{~cm}(\mathrm{y}=1,2, \ldots, 6$ - numbering from bottom of the transformer).

The selected measurement points lie on the two side walls of the transformer around one of transformer's core.

The basic characteristics for the AE signal recorded at the measurement point PA032 (area a) in the band of $20-70 \mathrm{kHz}$ are presented in Fig. 7. The properties of the recorded signal are as follows: the signal is periodic; it has the dominant frequency band of $20-40 \mathrm{kHz}$; in each period of the supply voltage, large signal values are arranged in wide "corridors" (Fig. 7c); on the averaged phase characteristics (Fig. 7b) the averaged values calculated for these corridors can be seen and, depending on the choice of the discrimination threshold value, there are two or four ranges of the reference voltage phases for which the MAE signals are recorded.
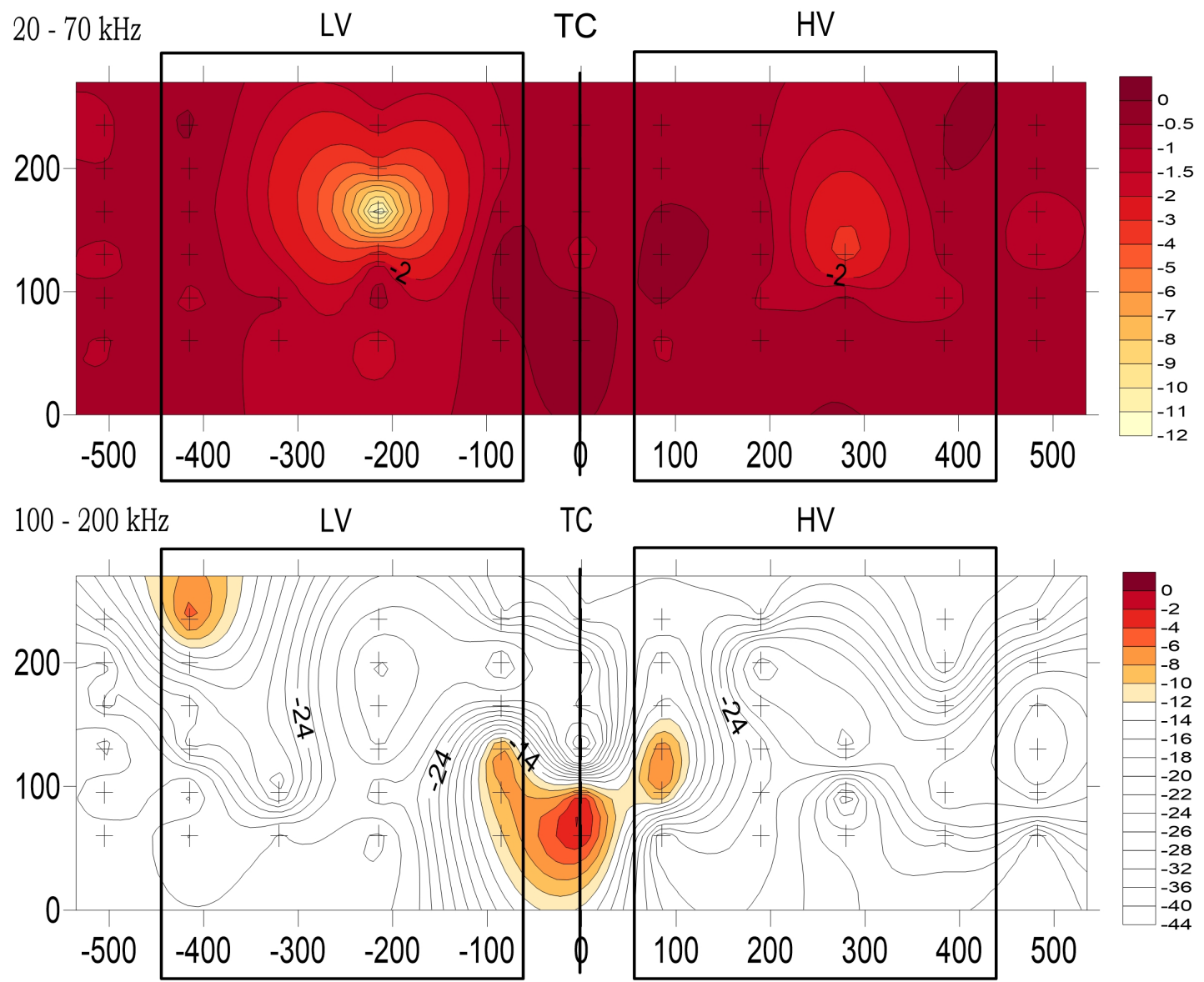

Fig. 6. Maps of ADC descriptor on the side walls of the tested transformer tank for the analysis of signals in selected frequency ranges: a) $20-70 \mathrm{kHz}$, b) $100-200 \mathrm{kHz}$; TP - tap changer, HV - part of the tank from higher voltage side, LV - part of the tank from lower voltage side, + - marked measuring points. 


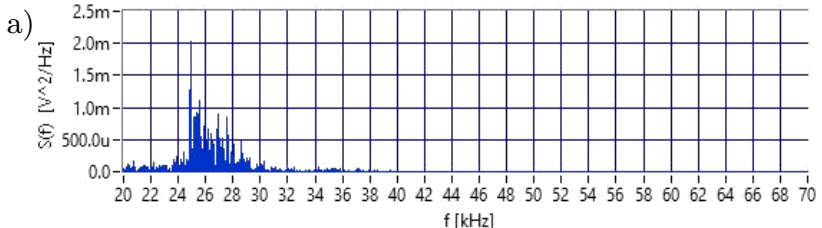

$\mathrm{f}[\mathrm{kHz}]$

c)

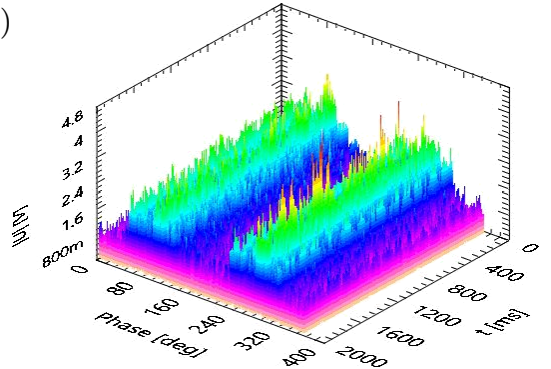

d)

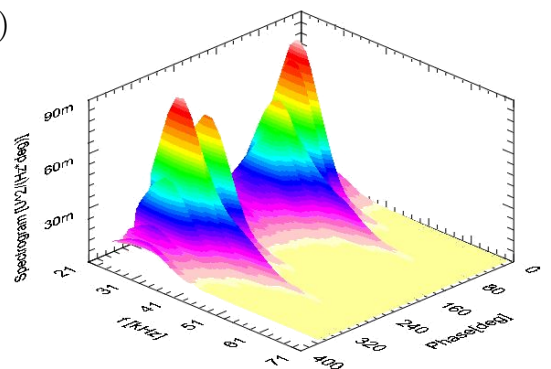

b)

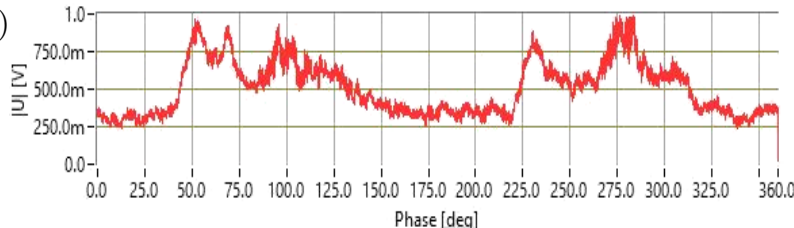

e)

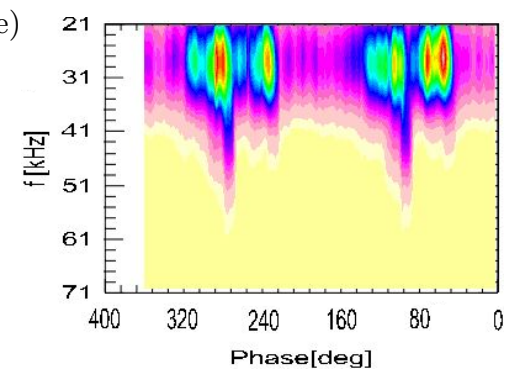

Fig. 7. Basic description of the AE signal recorded at the selected measurement point of the tested transformer (file PA032(2).BIN): a) frequency characteristic, b) averaged phase characteristic, c) phase-time characteristic, d) and e) averaged STFT spectrograms; ADC $=-1.21(20-70 \mathrm{kHz})$.

On the averaged phase characteristics (Fig. 7b) and averaged spectrogram (Figs. 7d and e) the asymmetry of the values and shape of the characteristics both for two and four corridors can be seen.

When selecting the value of the discrimination threshold as $500 \mathrm{mV}$, one can see in Fig. 7b two ranges of reference voltage phases equal to $\left(40^{\circ}, 135^{\circ}\right)$, $\left(225^{\circ}, 310^{\circ}\right)$, respectively, for which MAE signals are recorded at the measurement point PA032.

Increase in the value of the discrimination threshold to approx. $600-700 \mathrm{mV}$ results in distinguishing four ranges of reference voltage phases for which MAE signals are recorded. Two of them are within the phase range of $\left(40^{\circ}, 135^{\circ}\right)$ and two others are within the second phase range, namely $\left(225^{\circ}, 310^{\circ}\right)$. Such a location of ranges is associated with the respective parts of the magnetic hysteresis loop. Distinguishing two ranges determines the reference voltage phases for which the magnetic field takes the appropriate positive or negative values. Further division into four ranges corresponds to four parts of the magnetic hysteresis loop for which the magnetic field values increase and decrease within each of the two pre-determined ranges. Four ranges can be observed when the magnetoacoustic emission has one local maximum for each of the four parts of the hysteresis loop.

Additionally, the analysis of selected parts of the 20 -ms signal was performed. The analyzed part of the AE signal was filtered in different frequency bands. Figure 8 shows the results of that analysis for selected frequency ranges. After filtration in the band of 20 $70 \mathrm{kHz}$, one can distinguish two wide ranges (1-7 ms and $11-17 \mathrm{~ms}$ ) in which the analyzed signal has larger values (Fig. 8a). Taking into account the fact that the AE signals recorded at that measurement point had the dominant frequency band of $20-40 \mathrm{kHz}$, those signals were next filtered in the band of $40-70 \mathrm{kHz}$. Fil- tration of signals in that frequency range allowed distinguishing several single structures of duration equal to approx. 150-300 $\mu$ s (Fig. 8b).

At this stage of the analysis, it can be noted that the MAE signals recorded at the measurement point have the following characteristic features:

- they occur within wide ranges of phases,

- harmonics of frequencies $20-40 \mathrm{kHz}$ are dominant in the band of $20-70 \mathrm{kHz}$,

- single distinguished signals have durations of approx. $150-300 \mu \mathrm{s}$.

To better characterize the discussed phenomena, the AE signals recorded at measurement points PA02y $(\mathrm{y}=1,2, \ldots, 6$ - numbering from bottom of the transformer) were analyzed. These points are evenly distributed along one vertical line on the transformer tank.

The exact coordinates of the measurement points PA02y are given in Table 1 , column 2. This table contains the average values and mean standard deviations of the selected descriptors (ADP, ADC, ADNC, $\mathrm{U}_{\max }-\min$ and $\mathrm{U}_{\mathrm{rms}}$ ) for the signals recorded at the measurement points belonging to the family PA02y. The results shown in Table 1 are also presented in the graphical form in Fig. 9.

Figure 9 can be seen as the classification of the $\mathrm{AE}$ signal registered at measurement points belonging to the family PA02y made with the use of the two types of descriptors based on: the values measured directly $\left(U_{\max }-\min\right.$ and $\left.U_{\mathrm{rms}}\right)$, the physical phenomena (ADC, ADP and ADNC). A great similarity of both types of classification can be noted. For both types of descriptors minima of histograms occur for the values at the point of PA024, whereas in extreme points PA021 and PA026 descriptor values belong to the set of the largest values. 
a)

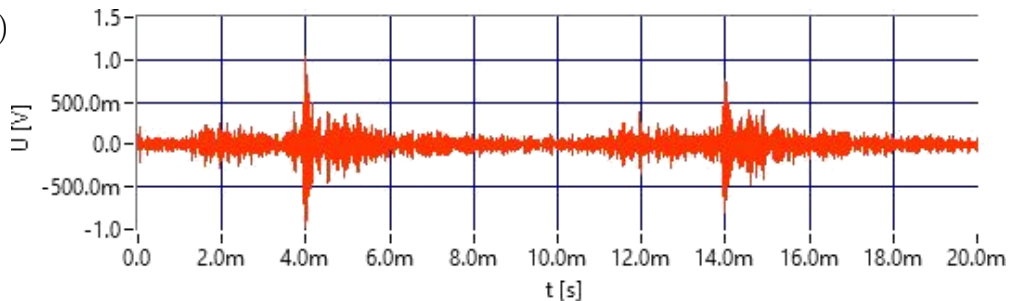

b)
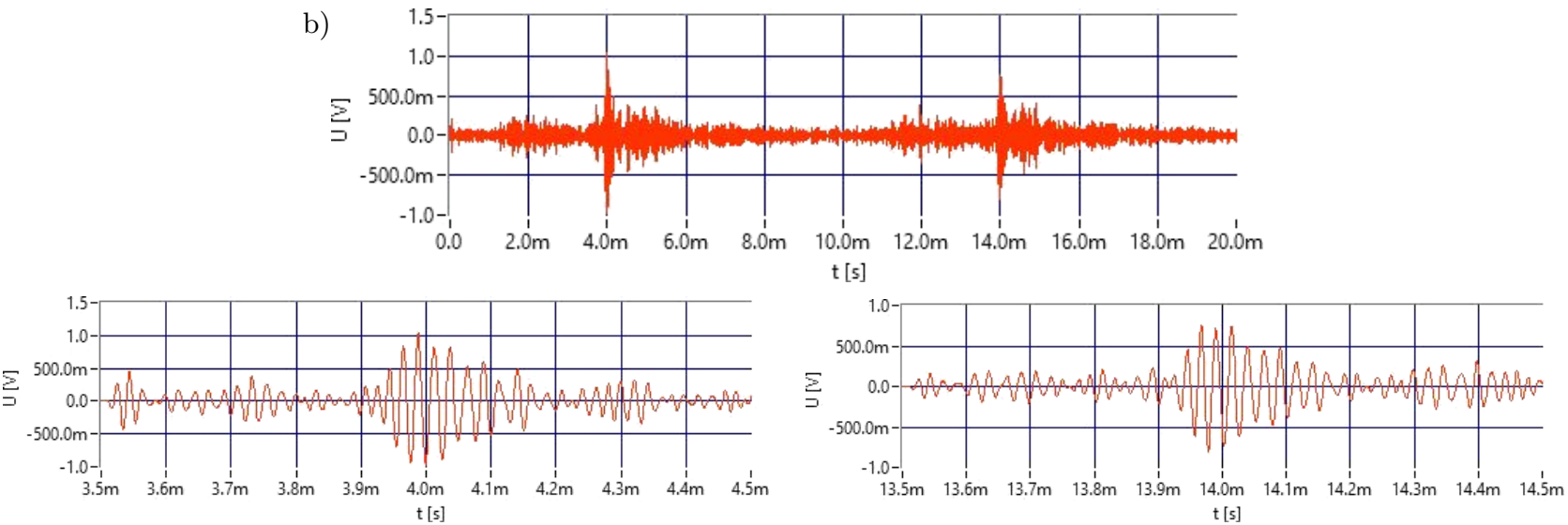

Fig. 8. Analysis of the selected part of the 20-ms signal recorded at the measurement point PA032: a) selected part of the signal after filtration in the band of $20-70 \mathrm{kHz}, \mathrm{b}$ ) selected part of the signal after filtration in the band of $40-70 \mathrm{kHz}$ together with the marked single structures.

Table 1. Values of selected descriptors for the AE signals recorded at measurement points PA02y - frequency band of $20-70 \mathrm{kHz}$.

\begin{tabular}{|c|c|c|c|c|c|c|c|c|c|c|c|}
\hline \multirow{2}{*}{ Name } & \multirow{2}{*}{$(X, Y)[\mathrm{cm}]$} & \multicolumn{2}{|c|}{ ADP [a. u.] } & \multicolumn{2}{c|}{ ADC [a.u.] } & \multicolumn{2}{c|}{ ADNC [a.u.] } & \multicolumn{2}{c|}{$U_{\max -\min }[\mathrm{V}]$} & \multicolumn{2}{|c|}{$U_{\text {rms }}[\mathrm{V}]$} \\
\cline { 3 - 14 } & & $a_{\text {av }}$ & $\sigma_{a}$ & $a_{\text {av }}$ & $\sigma_{a}$ & $a_{\text {av }}$ & $\sigma_{a}$ & $U_{\text {MM }}$ & $\sigma_{\text {MM }}$ & $U_{\text {rms }}$ & $\sigma_{\text {rms }}$ \\
\hline PA026 & $(483,235)$ & -0.54 & 0.02 & -0.63 & 0.02 & -0.71 & 0.02 & 13.87 & 0.73 & 1.07 & 0.01 \\
\hline PA025 & $(483,200)$ & -0.46 & 0.03 & -0.57 & 0.02 & -0.64 & 0.02 & 12.51 & 0.29 & 1.10 & 0.01 \\
\hline PA024 & $(483,165)$ & -1.28 & 0.07 & -1.38 & 0.06 & -1.47 & 0.06 & 6.79 & 0.28 & 0.60 & 0.02 \\
\hline PA023 & $(483,130)$ & -0.99 & 0.03 & -1.10 & 0.04 & -1.17 & 0.04 & 8.95 & 0.32 & 0.75 & 0.03 \\
\hline PA022 & $(483,95)$ & -0.72 & 0.04 & -0.82 & 0.03 & -0.91 & 0.03 & 9.68 & 0.30 & 0.87 & 0.04 \\
\hline PA021 & $(483,60)$ & -0.59 & 0.02 & -0.72 & 0.01 & -0.79 & 0.01 & 13.05 & 0.39 & 1.00 & 0.01 \\
\hline
\end{tabular}

a)

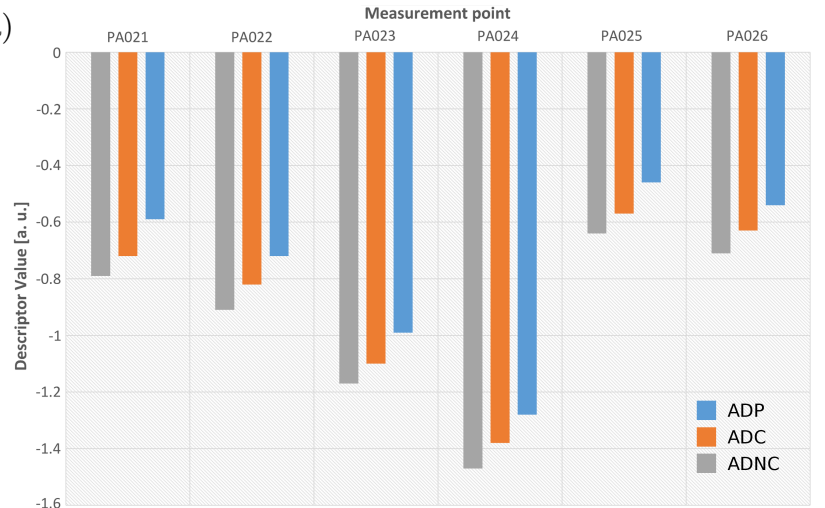

b)

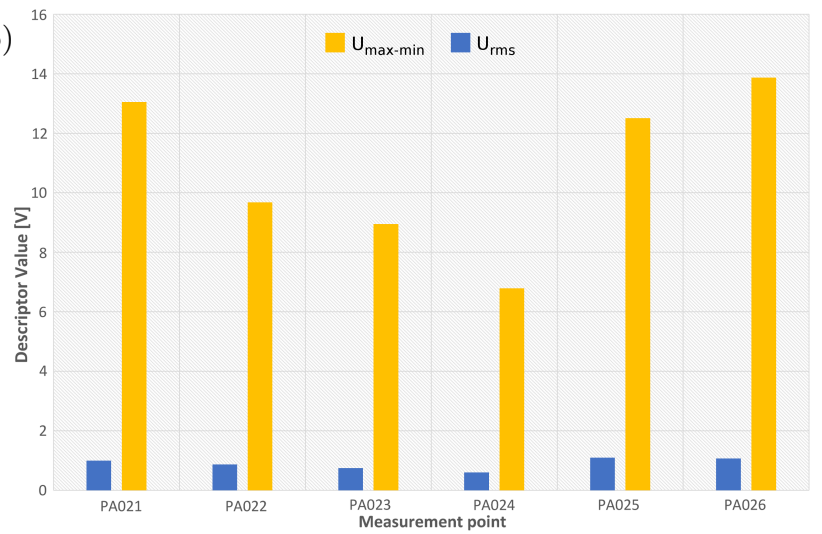

Fig. 9. Average values of the selected descriptors: a) ADP, ADC and ADNC, b) $U_{\max }-\min$ and $U_{\text {rms }}$ for the signals recorded at the measurement points belonging to the family PA02y. 
A more detailed analysis shows the differences between the classifications and this conclusion indicates further possibilities of correlation between the descriptors from ADC, APD and ADNC groups and the physical phenomena.

Basic characteristics were calculated for all the $\mathrm{AE}$ signals recorded at the measurement points belonging to the PA02y family. These characteristics for the signals recorded at the measurement points PA024 and PA026 (area b) in the band $20-70 \mathrm{kHz}$ are presented in Figs. 10 and 11. Points PA024 and PA026 were chosen as representative of the histogram in Fig. 9. The values of descriptors for signals recorded in these measurement points are respectively the minimum values or belonging to a set of greatest values.

The properties of these signals are similar to those of the AE signal recorded at the point PA032: the

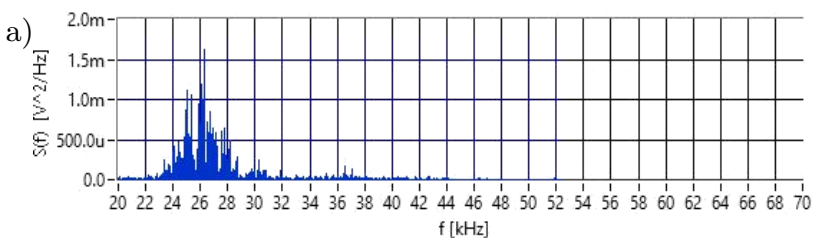

signals are periodic; their dominant frequency band is $20-40 \mathrm{kHz}$; in each period of the supply voltage, bands of phases of signal occurrence are arranged in wide "corridors" (Figs. 10c and 11c); one can distinguish two or four ranges of phases of the reference voltage for which the signals are recorded (Figs. 10b and $11 b)$.

To discuss the analysis results of the signals recorded at all the measurement points belonging to the family PA02y, there were chosen:

a) averaged phase characteristics,

b) STFT spectrograms projected onto phasefrequency plane.

These characteristics were calculated after filtering the signal in the bands $20-70 \mathrm{kHz}$ and $40-70 \mathrm{kHz}$. They are shown in Figs. 12 and 13.

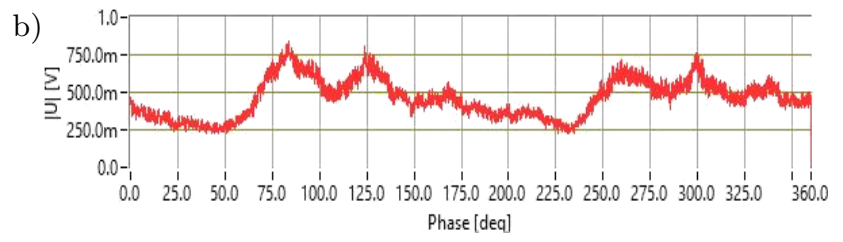

c)

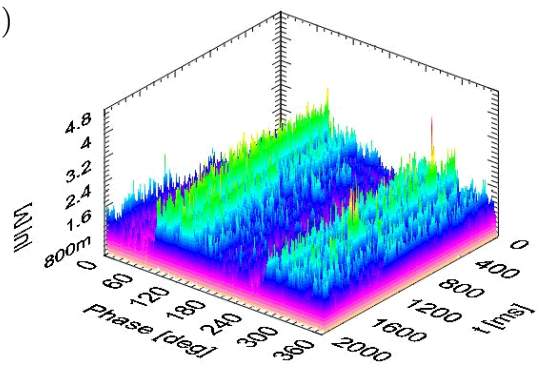

d)

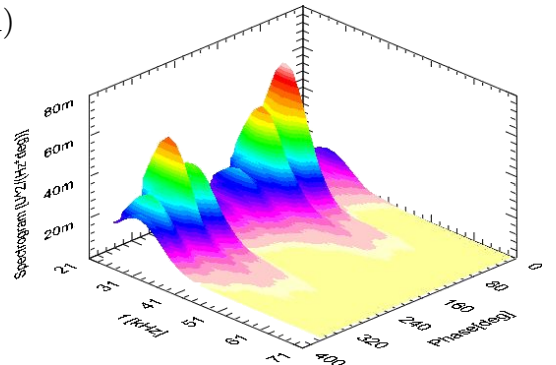

e)

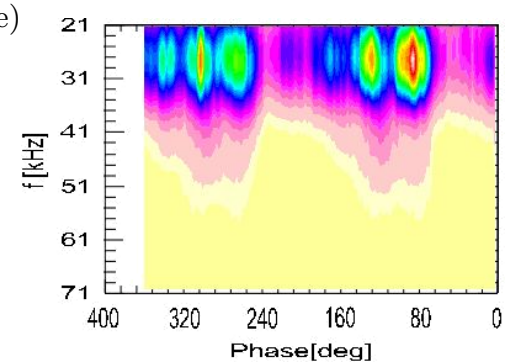

Fig. 10. Basic description of the AE signal recorded at the selected measurement point of the tested transformer (PA024) for filtration in the band 20-70 kHz: a) signal, b) frequency characteristic, c) phase-time characteristic, d) averaged phase characteristic, e) and f) averaged STFT spectrograms; $\mathrm{ADC}=-1.38$.

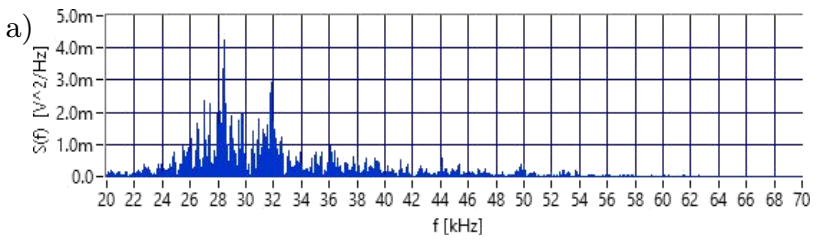
$\mathrm{f}[\mathrm{kHz}]$

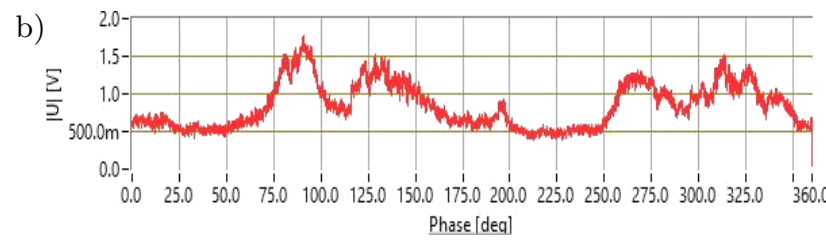
Phase [dea]

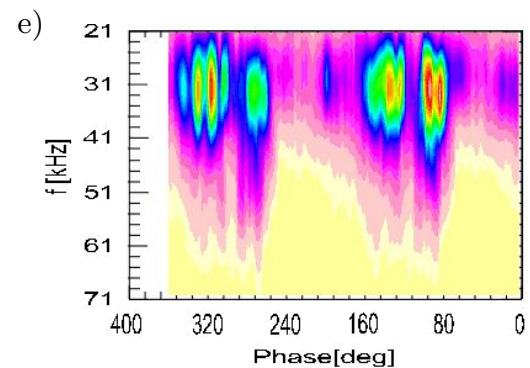

c)

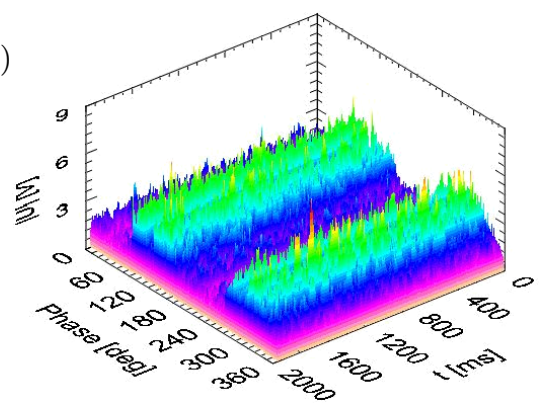

d)

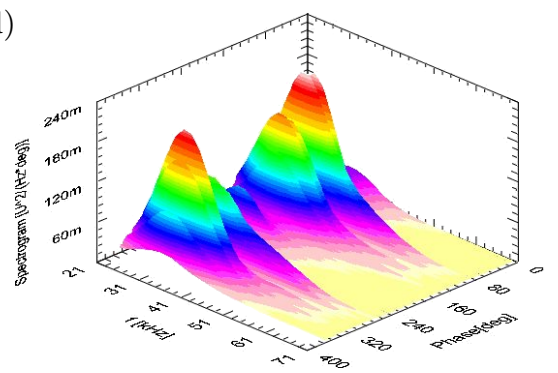

Fig. 11. Basic description of the AE signal recorded at the selected measurement point of the tested transformer (PA026) for filtration in the band 20-70 kHz: a) signal, b) frequency characteristic, c) phase-time characteristic, d) averaged phase characteristic, e) and f) averaged STFT spectrograms; $\mathrm{ADC}=-0.63$. 
a)
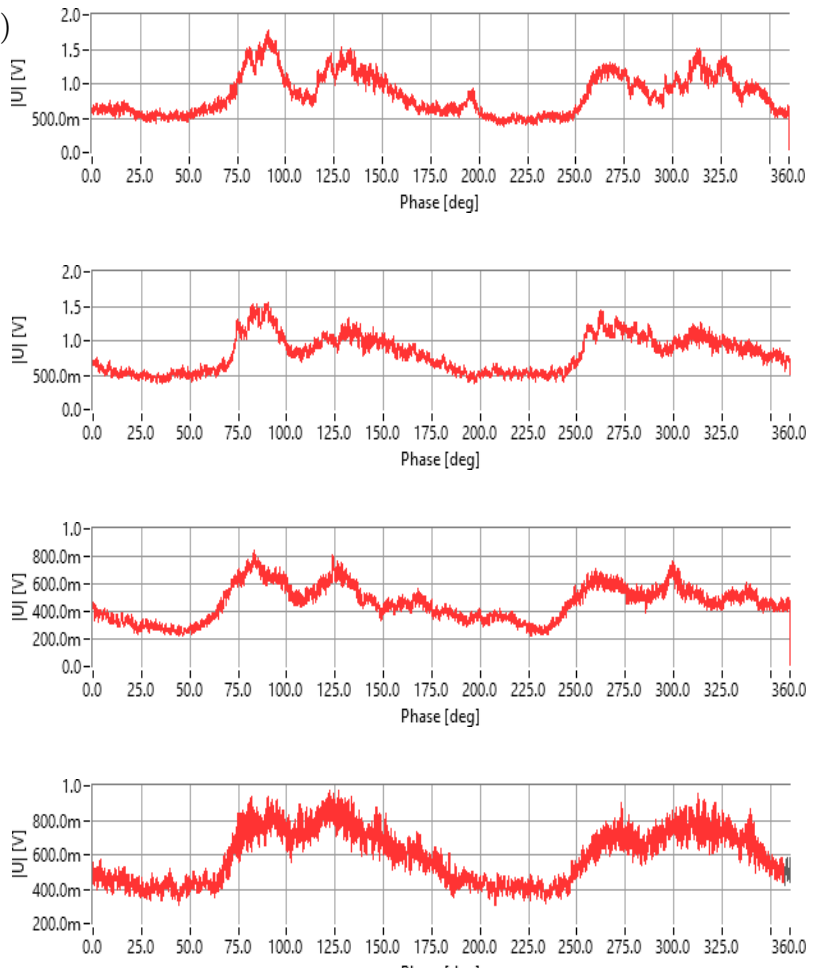
Phase [deg]
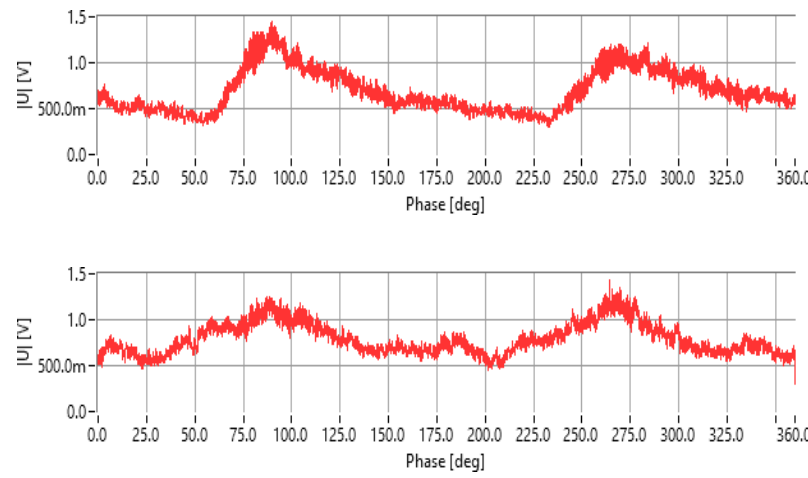

b)
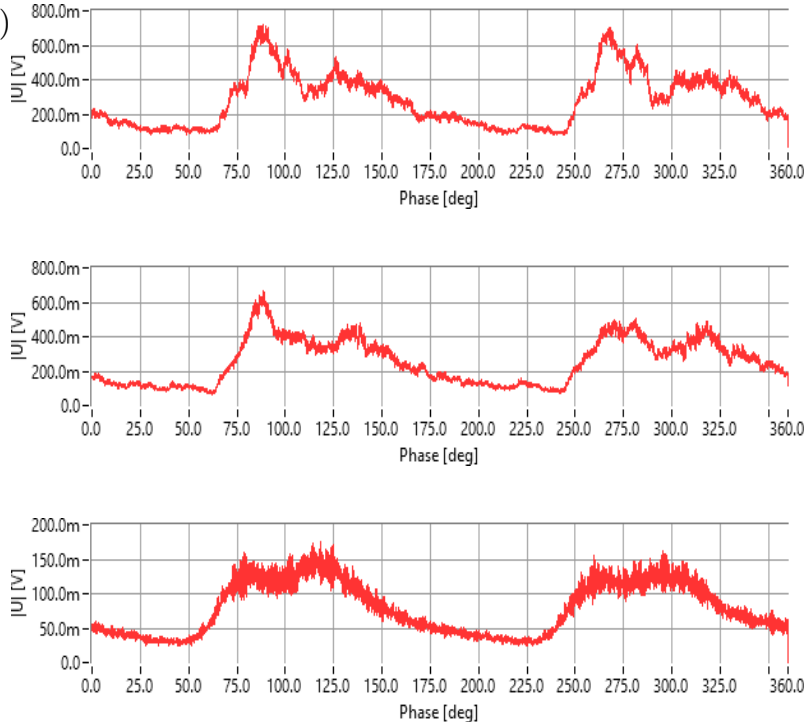
Phase [deg]
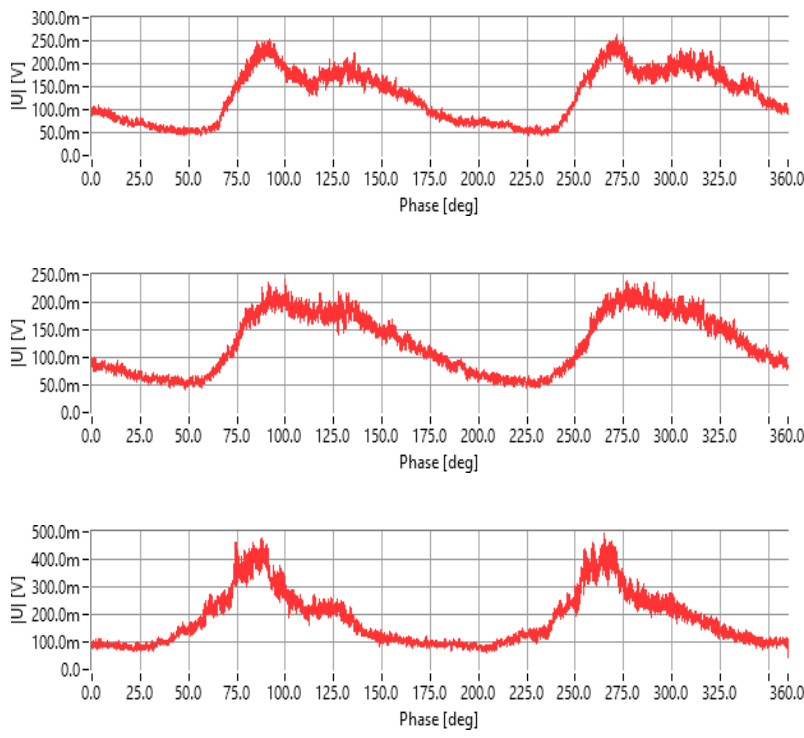

Fig. 12. Averaged phase characteristics for the family of AE signals recorded at the measurement points PA02y for the frequency band: a) $20-70 \mathrm{kHz}$, b) $40-70 \mathrm{kHz}$ (numbering of measurement points from bottom to top: y = 1, 2, ., 6).

The analysis of the properties of the averaged phase characteristics (Figs. 12a and b) when distinguishing two ranges of phases of the reference voltage shows for each range a fast increase in the values at the beginning of the range and significantly slower decrease of the signal at the end of the range. In addition, when analyzing the signal in the band of $20-70 \mathrm{kHz}$ it can be noted that the first maximum values in the first of the two distinguished ranges are larger than the first maximum values in the second range; such a regularity does not occur when analyzing the signal in the band of $40-70 \mathrm{kHz}$.

In a more detailed analysis which leads to separation of individual curves within each range (obtained from distinguishing two ranges), one should first designate the envelope and then see this envelope as a superposition of two or three Gaussian- type curves. With this approach, in each of the range there can be seen one Gaussian-type curve in the initial part of the range and one or two such curves in the further part of the range. Location of the maxima and the values of the maxima of these component curves give summary curves of different shapes with one or many maxima. With this approach, the curve of Fig. 12a for the point PA021 although having one maximum in the range, consists of at least two Gaussian-type curves, the second of which has a much lower amplitude than the first one. It follows from the asymmetric shape of this curve. This explanation allows to see that for the average characteristics of phase (Fig. 12) there are two fragments within curve containing two maxima separated by a relative minimum. These fragments correspond to the increase and decrease of the magnetic field, the min- 
a)
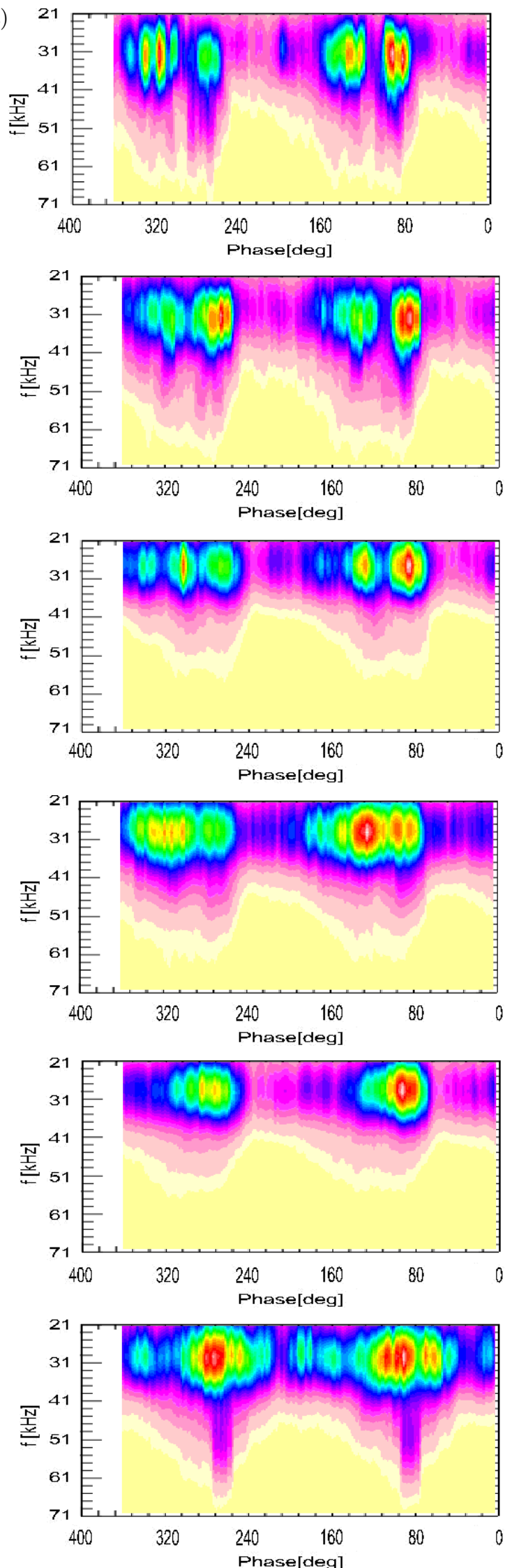
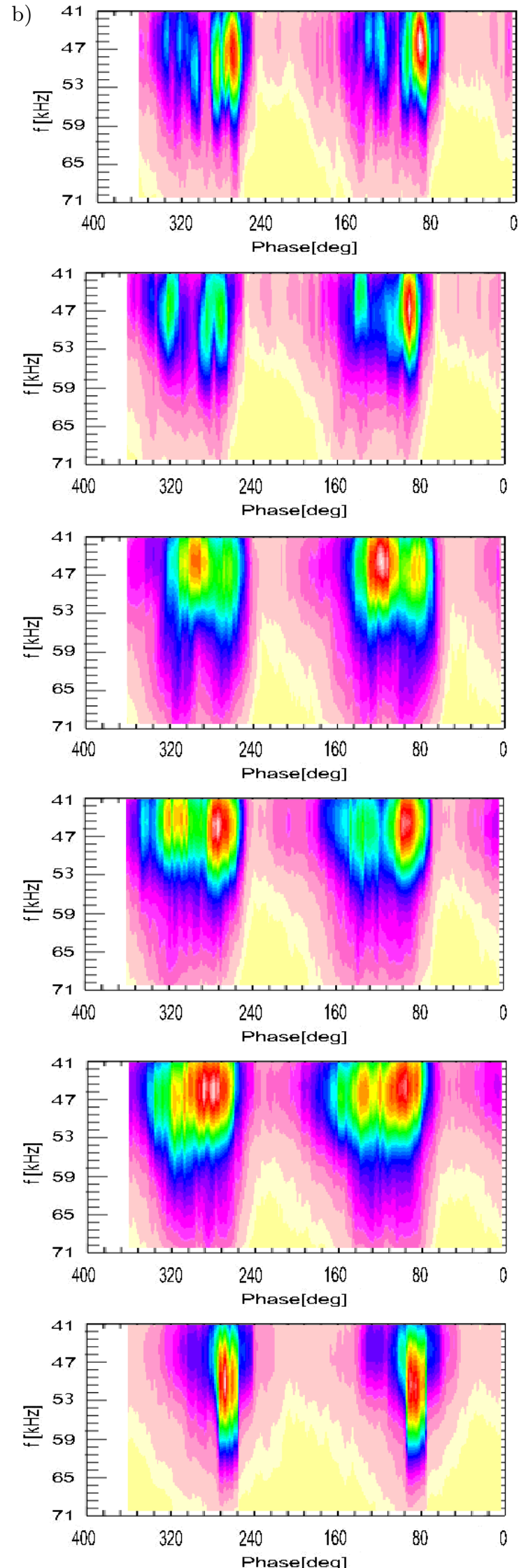

Fig. 13. STFT spectrograms projected onto phase-frequency plane for the family of AE signals recorded at measurement points PA02y for the frequency band: a) $20-70 \mathrm{kHz}$, b) $40-70 \mathrm{kHz}$ (numbering of measurement points from bottom to top: $\mathrm{y}=1,2, \ldots, 6)$. 
ima occur around the coercive field (GuYOT, CAGAN, 1993).

A detailed analysis of the positions of the minimum in Fig. 12a for PA026-24 points gives results within the following ranges phases: $\left(105^{\circ}, 115^{\circ}\right)$ and $\left(285^{\circ}, 295^{\circ}\right)$. These values define, therefore, the phase for the coercive field of studies. It is worth emphasizing that the phases shown in the diagrams describe the phases of the power supply used in the measurement system and do not specify the phase current flowing in the winding, which induces magnetic flux in the tested core.

Quantitative differences and qualitative differences in the shapes of the curves of the individual graphs in Fig. 12 contain information about the local magnetic properties of the tested materials.

A similar analysis can be performed for STFT spectrograms shown in Fig. 13. The higher sensitivity STFT spectrograms as compared to the averaged characteristics of the phase is visible.

Such an approach to the averaged phase characteristics of Figs. 12 and 13 allows concluding that the magnetoacoustic emission:

- distinguishes between the processes of magnetization and demagnetization,

- distinguishes between the processes of magnetization and demagnetization at positive and negative values of the magnetic field,

- shows the local properties of transformer core sheets.

To further characterize the AE signals coming from the phenomena occurring during magnetization of ferromagnetic materials, the analysis of the signals after filtration in the bands of $70-100 \mathrm{kHz}$ and $100-200 \mathrm{kHz}$ was conducted. From calculations, i.a., ADC and ADP descriptors values (Table 2 and Fig. 14) and averaged phase characteristics and STFT spectrograms - some of them are presented in Figs. 15 and 16 - were obtained.

Table 2. ADC and ADP descriptors values for the signals recorded at measurement points belonging to the PA02y family in selected frequency bands.

\begin{tabular}{|c|c|c|c|c|c|c|}
\hline \multirow{2}{*}{ Name } & \multicolumn{2}{|c|}{$20-70 \mathrm{kHz}$} & \multicolumn{2}{c|}{$70-100 \mathrm{kHz}$} & \multicolumn{2}{c|}{$100-200 \mathrm{kHz}$} \\
\cline { 2 - 8 } & $\begin{array}{c}\text { ADC } \\
\text { [a.u. }\end{array}$ & $\begin{array}{c}\text { ADP } \\
\text { [a.u. }\end{array}$ & $\begin{array}{c}\text { ADC } \\
\text { [a.u. }\end{array}$ & $\begin{array}{c}\text { ADP } \\
\text { [a.u.] }\end{array}$ & $\begin{array}{c}\text { ADC } \\
\text { [a.u. }\end{array}$ & $\begin{array}{c}\text { ADP } \\
\text { [a.u.] }\end{array}$ \\
\hline PA026 & -0.63 & -0.54 & -8.52 & -8.68 & -14.51 & -12.38 \\
\hline PA025 & -0.57 & -0.46 & -8.51 & -8.87 & -17.37 & -14.04 \\
\hline PA024 & -1.38 & -1.28 & -15.90 & -13.49 & -39.21 & -33.67 \\
\hline PA023 & -1.10 & -0.99 & -17.48 & -14.62 & -37.45 & -31.70 \\
\hline PA022 & -0.82 & -0.72 & -19.10 & -16.41 & -37.47 & -32.23 \\
\hline PA021 & -0.72 & -0.59 & -5.21 & -4.08 & -12.07 & -8.90 \\
\hline
\end{tabular}

The AE signals coming from these phenomena may have components outside the band $20-70 \mathrm{kHz}$. For the STFT spectrograms calculated after filtration in the a)

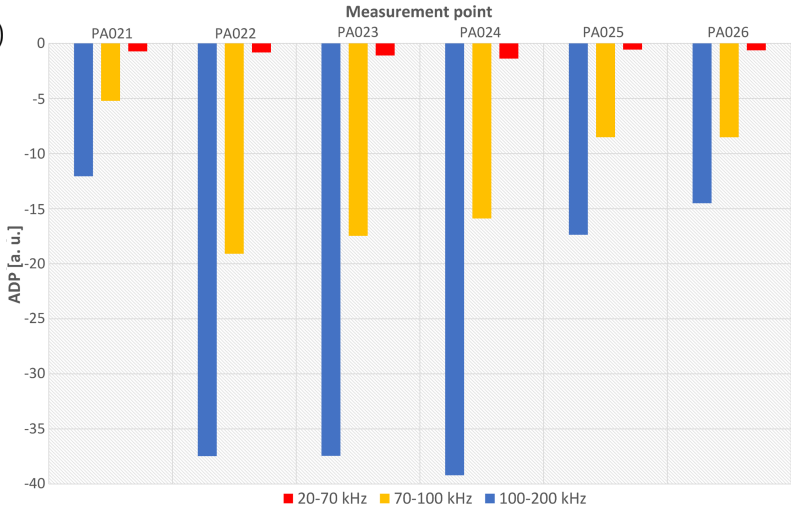

b)

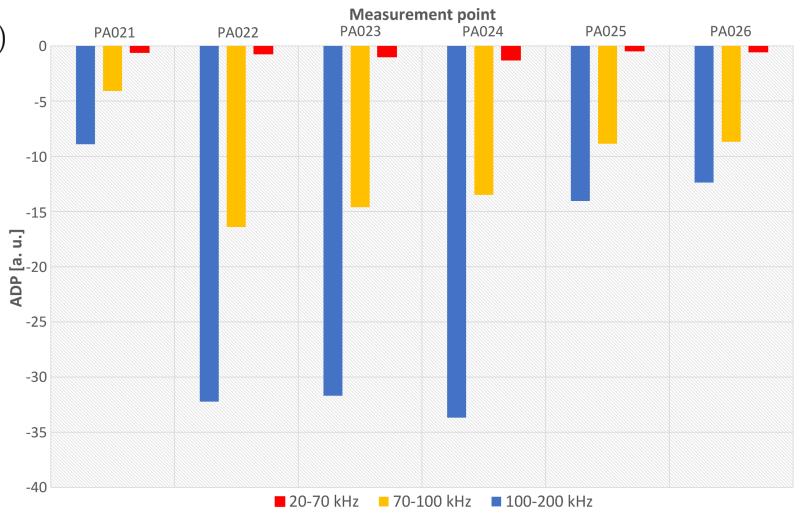

Fig. 14. Average values of descriptors: ADC (a), ADP (b) for the signals recorded at the measurement points belonging to the family PA02y in selected frequency bands.

band of $70-100 \mathrm{kHz}$ (Fig. 15a), the range of dominant frequencies extends up to $80-90 \mathrm{kHz}$. At some measurement points, the recorded signals have components also in the higher bands (Fig. 15b). Participation of signal harmonics in the band of $100-200 \mathrm{kHz}$, however, gets smaller and smaller. The low level of the advancement degree of AE signals in the band of $100-200 \mathrm{kHz}$ is confirmed by the ADC descriptor values calculated for the signals recorded at particular measurement points belonging to the family PA02y (Table 2). For the measurement points for which the maximum values of the amplitudes in the lower frequency bands were smaller (measurement points PA022, PA023, PA024), the signal amplitude in the range of $100-200 \mathrm{kHz}$ approaches the noise level of the measuring instruments.

From the conducted analyses it follows that the main band for the phenomena associated with magnetization of ferromagnetic materials can be extended up to $90 \mathrm{kHz}$.

The analysis of the selected parts of the signals of $20 \mathrm{~ms}$ duration recorded at particular measurement points was also performed. The analysis results for the signals recorded at the measurement points PA021 and PA026 and the frequency band of $40-70 \mathrm{kHz}$ are presented in Fig. 17. In both signals, the structures of duration of approx. 150-250 $\mu$ s each were distinguished. 

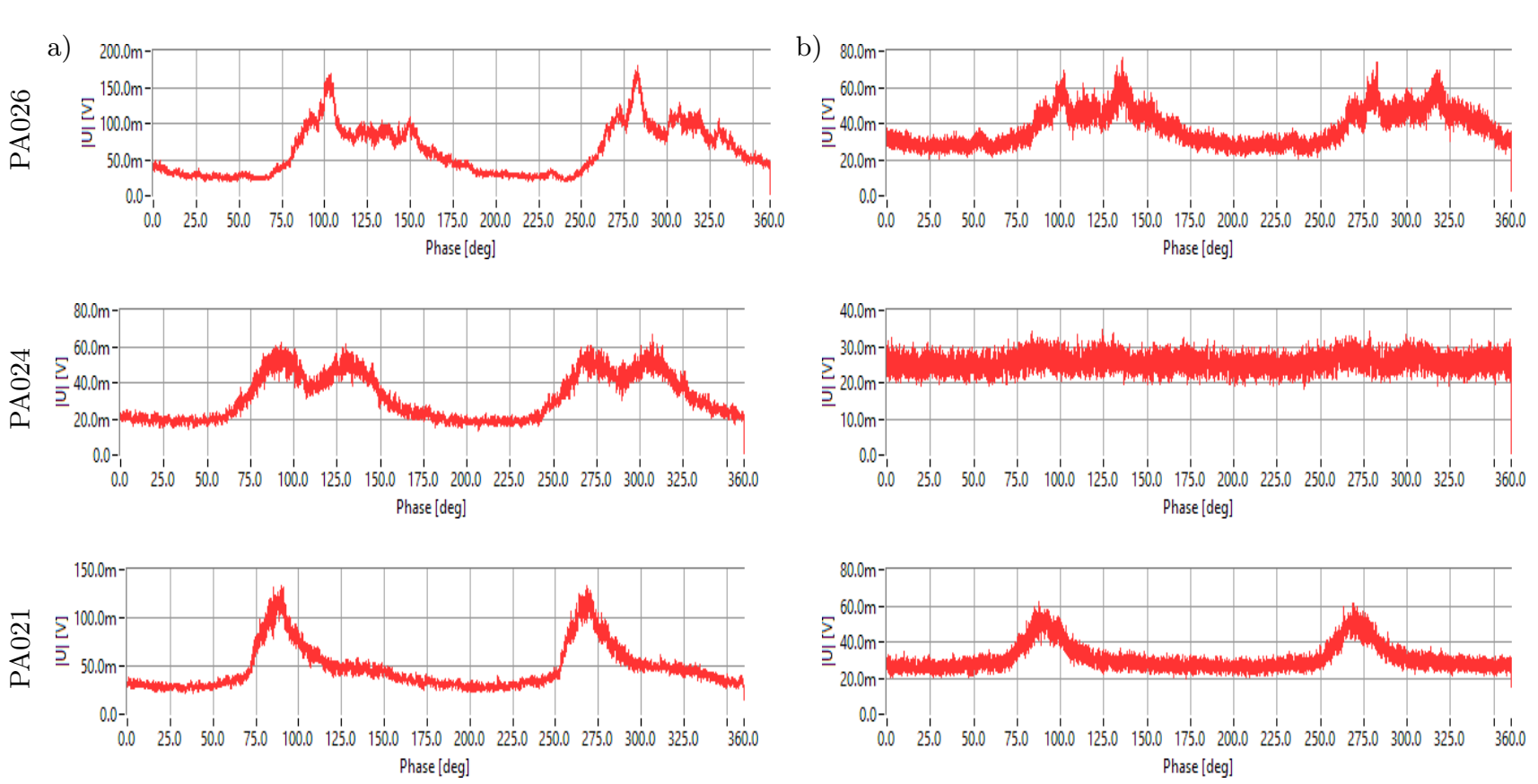

Fig. 15. Averaged phase characteristics for AE signals recorded at measurement points PA021, PA024 and PA026 for the frequency band: a) $70-100 \mathrm{kHz}$, b) $100-200 \mathrm{kHz}$.
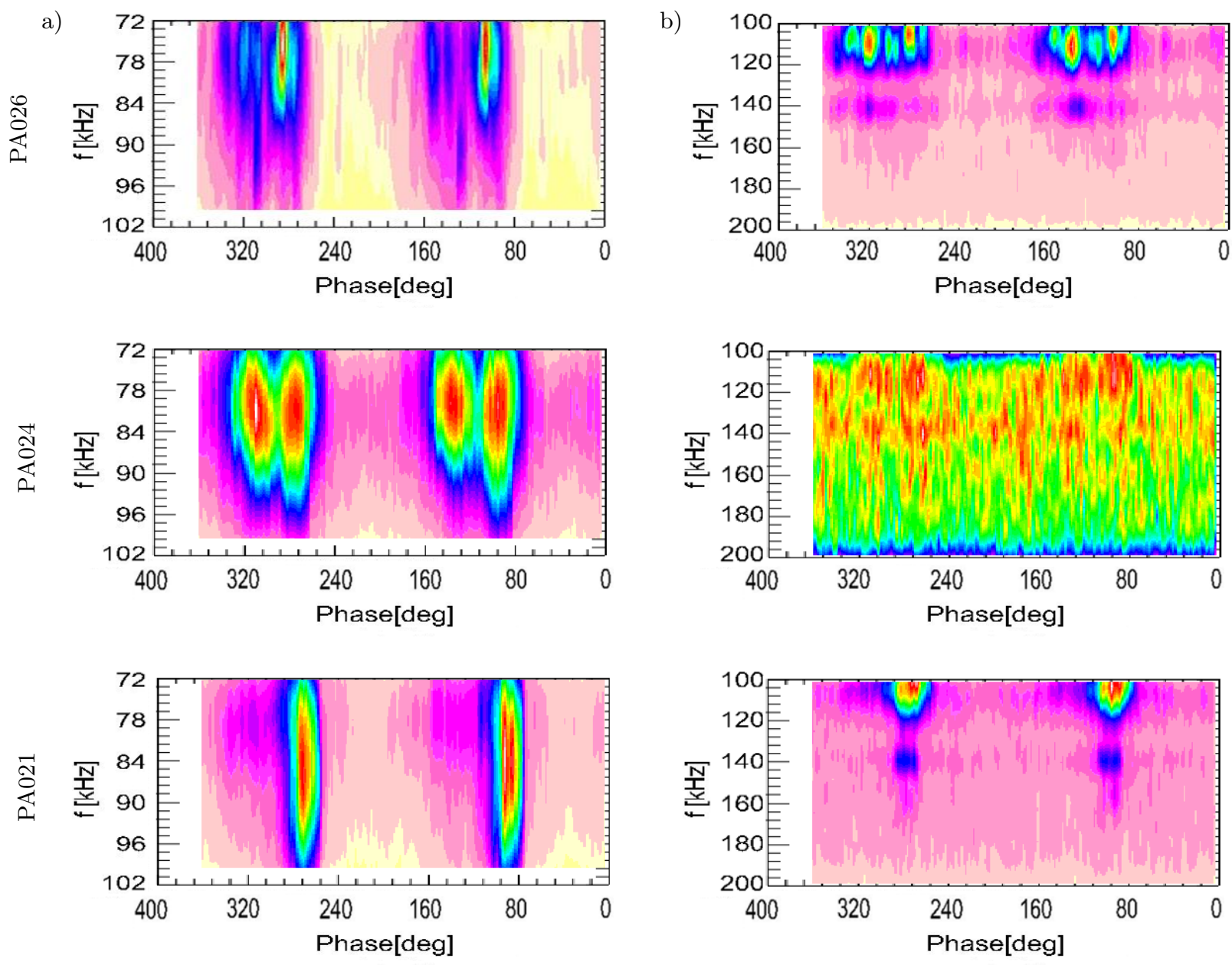

Fig. 16. STFT spectrograms projected onto phase-frequency plane for the AE signals recorded at measurement points PA021, PA024 and PA026 for the frequency band: a) $70-100 \mathrm{kHz}$, b) $100-200 \mathrm{kHz}$. 
a)
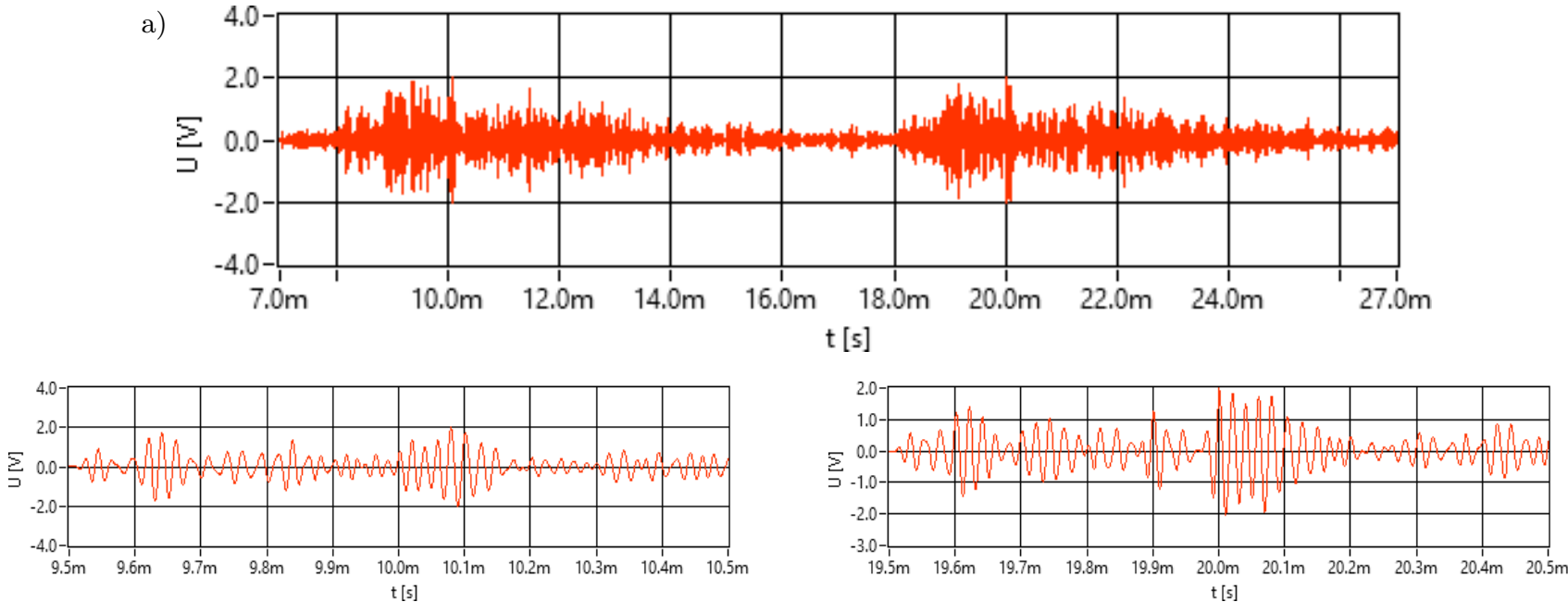

b)
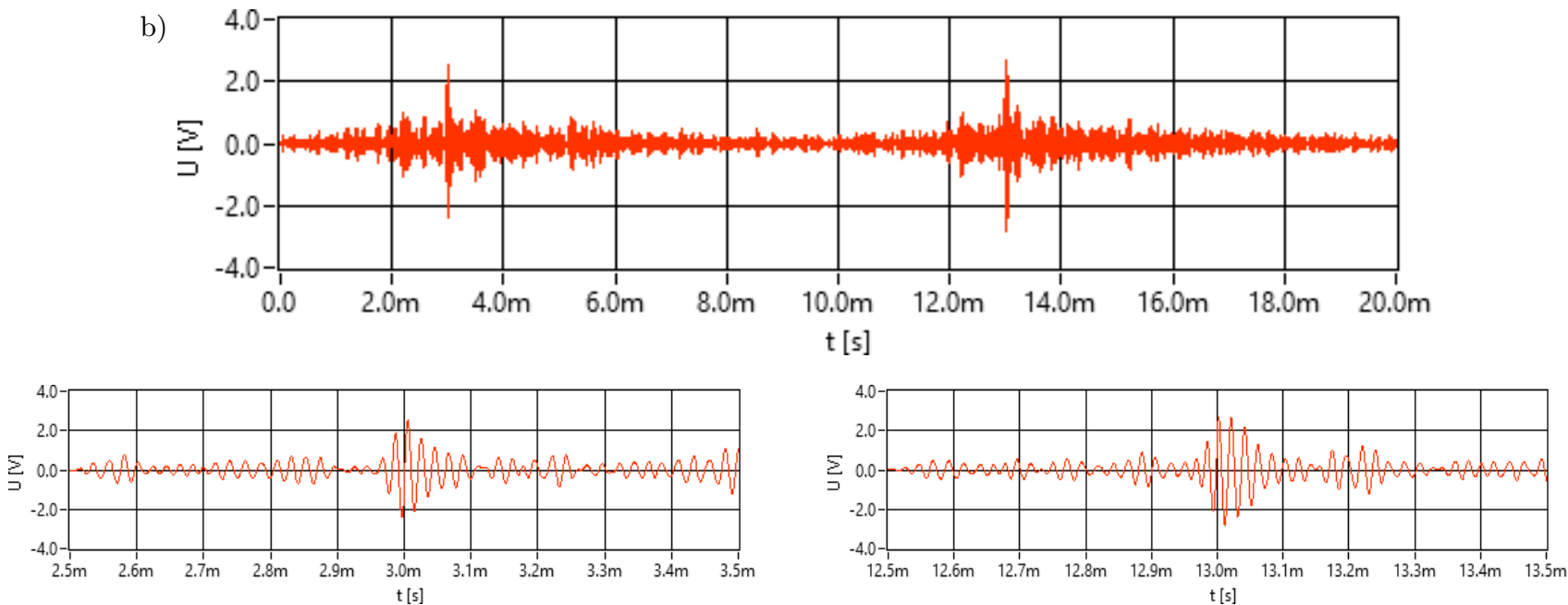

Fig. 17. Analysis of selected fragments of the 20-ms AE signals recorded at measurement points: a) PA026 $(X=483 \mathrm{~cm}$; $Y=235 \mathrm{~cm}), \mathrm{b}) \operatorname{PA} 021(X=483 \mathrm{~cm} ; Y=60 \mathrm{~cm})$. The selected fragment of the signal after filtration in the band of $40-70 \mathrm{kHz}$ together with the shown single structures.

\section{Conclusion}

The analysis of the AE signals coming from the phenomena associated with magnetization of ferromagnetic materials enabled drawing the precise conclusions concerning the following properties of magnetoacoustic signals:

- the main band for the phenomena associated with magnetization of ferromagnetic materials is $20-90 \mathrm{kHz}$ with the dominant harmonics of 20 $40 \mathrm{kHz}$,

- AE signals are recorded in wide ranges of phases,

- single MAE signals (if distinguishable) have durations of approx. 150-300 $\mu$ s.

The research results confirm that the magnetoacoustic emission:

- distinguishes between the processes of magnetization and demagnetization,
- distinguishes between the processes of magnetization and demagnetization at positive and negative values of the magnetic field,

- shows the local properties of transformer core sheets.

\section{References}

1. Augustyniak B. (1999), Correlation between acoustic emission and magnetic and mechanical Barkhausen effects, Journal of Magnetism and Magnetic Materials, 196-197, 799-801.

2. Bengtsson T., HakAn K., Jönsson B. (1997), Transformer PD diagnosis using Acoustic Emission Technique, 73-79.

3. Deheng Z., Kexiong T., Xianche J. (1988), The study of $A E$ method for detection of $P D$ in power transformers, II Conf. Properties and Application of Dielectric Materials, 614-617. 
4. Edwards C., Palmer S.B. (1987), The effect of stress and sample shape on the magnitude and frequency of magnetomechanical acoustic emission, The Journal of the Acoustical Society of America, 82, 2, 534-544.

5. Guyot M., Cagan V. (1993), The magneto-acoustic emission, J. Appl. Phys., 73, 10, 5348-5353.

6. Howells E., Norton E.T. (1978), Detection of Partial Discharges in Transformers Using Acoustic Emission Techniques, IEEE Trans. on Power Apparat. and Systems, PAS-97, 5, 1538-1549.

7. Lord A.E. (1975), Physical Acoustics: Principles and Methods, Academic Press.

8. Piotrowski L., Augustyniak B., Chmielewski M. (2012), Recent development in material state evaluation with the use of magnetoacoustic emission effect measurements [in Polish: Stan rozwoju metody diagnozowania materiatów z wykorzystaniem efektu emisji magnetoakustycznej], Przegląd Spawalnictwa, 13, 24-30.

9. Witos F., Gacek Z., Opilski A. (2002), The new $A E$ descriptor for modeled sources of PDs, Archives of Acoustic, 27, 1, 65-77.
10. Witos F. (2008), Investigation of partial discharges by means of acoustic emission method and electric method [in Polish: Badania wyladowań niezupetnych metoda emisji akustycznej $i$ metoda elektryczna], Wydawnictwo Politechniki Śląskiej, Gliwice.

11. Witos F., Olszewska A. (2012), The system useful for analysis of acoustic emission signals generated by partial discharges within power oil transformers insulation [in Polish: System do analizy sygnatów emisji akustycznej generowanych przez wyładowania niezupetne $w$ izolacji transformatorów elektroenergetycznych], Przegląd Elektrotechniczny, 88, 11B, 154157.

12. Olszewska A., Witos F. (2012), Location of partial discharge sources and analysis of signals in chosen power oil transformers by means of acoustic emission method, Acta Physica Polonica A, 122, 1, 921-926.

13. Witos F., GaceK Z. (2013), Testing of partial discharges and location of their sources in generator coil bars by means of acoustic emission and electric methods, [in:] Acoustic emission - research and applications, W. Sikorski [Ed.], pp. 117-145, InTech, Rijeka. 